\title{
Cardiotomy suction, but not open venous reservoirs, activates coagulofibrinolysis in coronary artery surgery
}

\author{
Atsushi Nakahira, MD, PhD, ${ }^{\text {a }}$ Yasuyuki Sasaki, MD, PhD, ${ }^{\text {a }}$ Hidekazu Hirai, MD, PhD, ${ }^{\text {a }}$ Mitsunori Matsuo, ${ }^{\mathrm{b}}$ \\ Akimasa Morisaki, MD, ${ }^{\mathrm{a}}$ Shigefumi Suehiro, $\mathrm{MD}, \mathrm{PhD},{ }^{\mathrm{a}}$ and Toshihiko Shibata, $\mathrm{MD}, \mathrm{PhD}^{\mathrm{a}}$
}

\begin{abstract}
Objectives: Closed and miniaturized cardiopulmonary bypass circuits, which eliminate cardiotomy suction and open venous reservoirs with a reduced priming volume, have been reported to be advantageous. We comparatively examined the respective contribution of cardiotomy suction and open venous reservoirs to perioperative activation in coagulofibrinolysis and inflammation systems, with identical conditions of priming volume and anticoagulation.
\end{abstract}

Methods: A total of 75 consecutive coronary artery bypass grafting procedures were performed using 1 of the following 3 cardiopulmonary bypass circuits under identical conditions of priming volumes, heparin coating, and protocols of anticoagulation and transfusion, as follows: a circuit with an open venous reservoir and cardiotomy suction (open group, $\mathrm{n}=25$ ), a circuit with an open venous reservoir without cardiotomy suction (nonsuction group, $\mathrm{n}=25$ ), or a circuit without either (closed group, $\mathrm{n}=25$ ). Blood samples were collected at 8 points up to the first postoperative morning.

Results: The thrombin-antithrombin III complex, fibrinogen degeneration products, D-dimer, plasmin- $\alpha 2$ plasmin inhibitor complex, and plasminogen activator inhibitor-1 levels were significantly greater in the open group than those in the other 2 groups $(P<.0001$, for all markers). The C3a and interleukin-6 levels were similar among all the groups. The incidences of perioperative transfusion and postoperative bleeding were increased and the early graft patency rate of saphenous veins was lower in the open group than those in the other 2 groups.

Conclusions: Cardiotomy suction, but not open venous reservoirs, causes perioperative coagulofibrinolysis activation, although neither affects the inflammation system. The use of cardiotomy suction needs to be examined further in association with postoperative PAI-1 elevation and early vein graft occlusion. (J Thorac Cardiovasc Surg 2011;141:1289-97)

Closed and miniaturized cardiopulmonary bypass (CPB) circuits, which have recently been applied, particularly in coronary artery bypass grafting (CABG), appear to be a fundamental and important innovation in CPB technology. ${ }^{1-7}$ These circuits are not equipped with cardiotomy suction or open venous reservoirs and, consequently, enable extreme miniaturization of the circuit. In clinical studies, these circuits have been shown to improve the clinical outcomes and suppress various perioperative plasma markers compared with conventional open circuits ${ }^{1,2}$ and, furthermore, have been comparable to those found during off-pump CABG (OPCAB). ${ }^{4,5}$ The advantageous outcome

\footnotetext{
From the Department of Cardiovascular Surgery, ${ }^{\text {a }}$ Osaka City University Graduate School of Medicine, and the Department of Extracorporeal Circulation, ${ }^{\mathrm{b}}$ Osaka City University Hospital, Osaka, Japan.

Dr Nakahira received support from the 106th Annual Congress of Japan Surgical Society Memorial Surgical Research Fund.

Disclosures: Authors have nothing to disclose with regard to commercial support.

Received for publication March 21, 2010; revisions received July 1, 2010; accepted for publication July 13, 2010; available ahead of print Aug 30, 2010.

Address for reprints: Atsushi Nakahira, MD, PhD, Department of Cardiovascular Surgery, Osaka City University Graduate School of Medicine, 1-4-3 Asahimachi Abeno-ku, Osaka 545-8585 Japan (E-mail: osushi123@med.osaka-cu.ac.jp). $0022-5223 / \$ 36.00$

Copyright (C) 2011 by The American Association for Thoracic Surgery doi:10.1016/j.jtcvs.2010.07.024
}

of closed and miniaturized circuits is supposedly derived from the following 3 components: the elimination of cardiotomy suction, the elimination of open venous reservoirs, and the extreme miniaturization of the circuit.

The activation of coagulofibrinolysis and inflammation systems are important issues in cardiac surgeries using CPB and lead to various adverse outcomes, particularly in high-risk patients. ${ }^{8,9}$ Thrombin is a key enzyme in these systems, ${ }^{9}$ and anticoagulation with heparin is essential during $\mathrm{CPB} .{ }^{10}$ Even with standard heparinization and heparin-coated circuits, thrombin generation is inevitable in cardiac surgeries using $\mathrm{CPB} .{ }^{9-11}$ Cardiotomy suction and open venous reservoirs have been demonstrated to contribute to the activation of the coagulofibrinolysis and inflammation systems ${ }^{12-16}$; however, the contribution of each has not yet been comparatively examined. ${ }^{7}$ In the use of closed and miniaturized circuits, highly sophisticated miniaturization can also affect the coagulofibrinolysis and inflammation systems owing to the prevention of hemodilution and a reduction of the blood-circuit contact area. ${ }^{17}$

In the present prospective clinical study, we compared the respective effect of cardiotomy suction and open venous reservoirs on the coagulofibrinolysis and inflammation systems, setting identical conditions of priming volumes, 


$$
\begin{aligned}
& \text { Abbreviations and Acronyms } \\
& \text { ACT = activated clotting time } \\
& \text { APTT = activated partial thromboplastin time } \\
& \mathrm{AT}=\text { antithrombin III } \\
& \text { CABG = coronary artery bypass grafting } \\
& \mathrm{CPB}=\text { cardiopulmonary bypass } \\
& \text { FDPs = fibrinogen degeneration products } \\
& \text { IL } \quad=\text { interleukin } \\
& \mathrm{OPCAB}=\text { off-pump CABG } \\
& \text { PAI-1 = plasminogen activator inhibitor-1 } \\
& \text { PIC }=\text { plasmin }-\alpha 2 \text { plasmin inhibitor complex } \\
& \text { PRBCs }=\text { packed red blood cells } \\
& \text { PT }=\text { prothrombin time } \\
& \text { TAT }=\text { thrombin-antithrombin III complex }
\end{aligned}
$$

heparin coating, and protocols of anticoagulation and transfusion.

\section{MATERIALS AND METHODS \\ Study Population}

Between October 2006 and June 2009, 75 elective, primary, isolated CABGs at Osaka City University Hospital (Osaka, Japan) were prospectively randomized for use of 1 of the following CPB circuits: a circuit with an open venous reservoir and cardiotomy suction (open group, $\mathrm{n}=25$ ), a circuit with an open venous reservoir without cardiotomy suction (nonsuction group, $\mathrm{n}=25$ ), or a circuit without either (closed group, $\mathrm{n}=25$ ). The exclusion criteria included single-vessel disease, preoperative administration of heparin, coagulofibrinolysis disorders, renal or liver dysfunction, and inflammatory or malignant disease. Anticoagulants and antiplatelet agents were discontinued at least 7 days before surgery. The institutional review board at our institution approved the study, and all patients provided informed consent for the study.

\section{Study Protocols}

Anesthetic protocol and operative procedure. A standardized anesthetic protocol was used. No premedication was administered. Anesthesia was induced with intravenous midazolam and fentanyl and maintained with fentanyl, propofol, vecuronium bromide, and inhalation of sevoflurane. No patient received perioperative corticosteroids, aprotinin, or tranexamic acid.

A median sternotomy approach was used for all patients. The left internal thoracic artery and other graft materials were harvested simultaneously. After systemic heparinization, CPB was established with an arterial cannula to the ascending aorta and a 2-stage cannula through the right atrial appendage. To avoid air entrainment and leaky bleeding through the purse-string suture around the venous cannula, an extra tie was added around the insertion site of the atrial appendage. A left ventricular vent was inserted through the right upper pulmonary vein. During CPB, a nonpulsatile flow of $2.4 \mathrm{~L} / \mathrm{min} / \mathrm{m}^{2}$ body surface area was maintained under moderate systemic hypothermia (rectal temperature, $32^{\circ} \mathrm{C}$ ), and the mean arterial pressure was controlled within the range of 50 to $80 \mathrm{~mm} \mathrm{Hg}$.

After aortic crossclamping, identical cold blood cardioplegia was administered through the aortic root, followed by intermittent administration in the antegrade and retrograde directions. All proximal, as well as distal, coronary anastomoses were constructed using hand suturing during 1 aortic clamping. After termination of $\mathrm{CPB}$ and achievement of hemostasis, all patients were postoperatively admitted to the intensive care unit. The blood from the postoperative chest drains was discarded.

CPB circuits and suction strategy. The circuits in all groups consisted of a hollow-fiber membrane oxygenator (Affinity NT Oxygenator, CB511), a centrifugal blood pump (Bio-Pump, CBBPX80), and an arterial filter (Affinity Arterial Filter, CB351; all 3 components from Medtronic Cardiac Surgery, Minneapolis, Minn). All the components of the circuits in all groups were coated with covalently-bonded heparin (Carmeda BioActive Surface, Carmeda AB, Upplands Vasby, Sweden). The circuits in all the groups were primed with identical fluid $(1300 \mathrm{~mL})$, a mixture of $1000 \mathrm{~mL}$ lactated Ringer's solution, $200 \mathrm{~mL}$ mannitol $(200 \mathrm{mg} / \mathrm{mL})$, and $100 \mathrm{~mL}$ sodium bicarbonate $(84 \mathrm{mg} / \mathrm{mL})$. The differences in the circuits and suction strategy among the groups are described below and shown in Figure 1.

Open group. For the open group, the circuit contained a hard-shell venous reservoir (Affinity CVR Reservoir, 61399409462, Medtronic Cardiac Surgery). During systemic heparinization, pericardial blood was collected in the reservoir through cardiotomy suction. At all other times, the pericardial suction blood was processed by an autotransfusion cell-saving device (Electa with a bowel of BT225, Dideco, Sorin Group, Mirandola, Italy) and transfused.

Nonsuction group. For the nonsuction group, the circuit contained a hard-shell venous reservoir just as in the open group. Cardiotomy suction was not used, and a cell-saving device was applied throughout the operation. Closed group. For the closed group, the circuit was designed using the basic structure of the Medtronic Resting Heart System (Medtronic Cardiac Surgery). The circuit eliminated an open venous reservoir and was equipped with a collapsible soft reservoir in the side of venous return for temporary blood retention. Cardiotomy suction was not used, and a cell-saving device was applied throughout the operation.

Anticoagulation and blood product use. The protocols for anticoagulation and blood product use were similar for all groups. Before aortic cannulation, all patients received $300 \mathrm{IU} / \mathrm{kg}$ bovine heparin. The celite-activated activated clotting time (ACT; Hemochron 801, International Technidyne Corp, Edison, NJ) was used to guide heparin anticoagulation, and the ACT was maintained at 400 seconds or more by the additional administration of heparin, as required. After the termination of $\mathrm{CPB}$, the heparin was neutralized with $4.5 \mathrm{mg} / \mathrm{kg}$ of protamine.

Packed red blood cells (PRBCs) were transfused to maintain the hematocrit at $23 \%$ or more during $\mathrm{CPB}$ and $28 \%$ or more after the termination of CPB.

Data collection and measurements. Blood samples were obtained from a radial arterial catheter or the arterial side of the CPB circulation at the following 8 observation times: T1, before the induction of anesthesia; T2, 1 hour after the initiation of CPB; T3, 10 minutes after aortic declamping; T4, 5 minutes after protamine administration; T5, T6, and T7, 1,3 , and 6 hours after the termination of $\mathrm{CPB}$, respectively; and $\mathrm{T} 8$, the first postoperative morning. The hematocrit and platelet count were immediately measured using an automated cell counter (MAXM-Retic, Beckman Coulter, Inc, Fullerton, CA). The other citrated samples were centrifuged at $3000 \mathrm{~g}$ for 10 minutes, and the plasma was stored at $-80^{\circ} \mathrm{C}$ for later analysis.

The coagulation, fibrinolysis, and inflammation markers were measured using reagents according to the manufacturer's instructions, as follows. The activated partial thromboplastin time (APTT) was measured using the Langdell method and Hemosil SynthASil (Instrumentation Laboratory, Bedford, MA). The prothrombin time (PT) was determined using the 1-stage method of Quick using Thromborel S (Sysmex Corp, Hyogo, Japan). Antithrombin III (AT) was determined using the absorbance photometry method for chromogenic substrates using Testzyme S ATIII (Sekisui Medical Corp, Tokyo, Japan). The plasma thrombin-antithrombin III complex (TAT) levels, which reflect the amount of thrombin generated in the circulating blood, were measured using an enzyme-linked immunoassay method and TAT [S] (TFB Inc, Tokyo, Japan). The plasma levels of fibrinogen degeneration products (FDPs) were determined using an absorbance photometry method for latex turbidimetry tests and Nanopia P-FDP (Sekisui Medical Corp, Tokyo, 


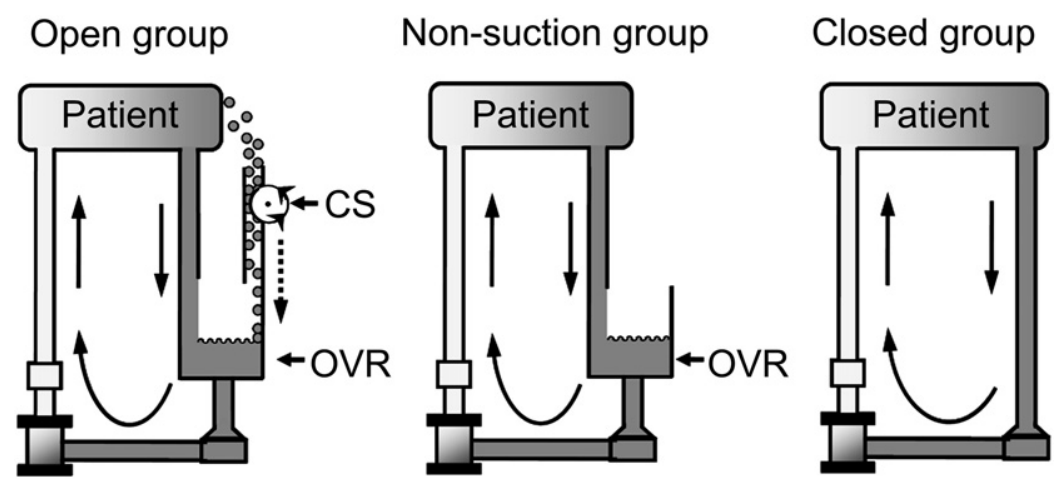

FIGURE 1. Schema showing components of cardiopulmonary bypass circuits in each group. Circuit in open group consisted of open venous reservoir (OVR) and cardiotomy suction $(C S)$; circuit in nonsuction group consisted of OVR without CS; and circuit in closed group consisted of neither OVR nor CS.

Japan). The plasma levels of D-dimer, plasmin- $\alpha 2$ plasmin inhibitor complex (PIC), and plasminogen activator inhibitor-1 (PAI-1) were measured using a latex photometric immunoassay and LPIA-ACE D-dimer, LPIA PPIII, and LPIA tPAI test, respectively (Mitsubishi Chemical Medience Corp, Tokyo, Japan). C3a was measured by radioimmunoassay using the human complement C3a des Arg EIA Kit (Assay Designs Inc, Ann Arbor, MI). The serum levels of interleukin (IL)-6 were measured with the chemiluminescent enzyme immunoassay technique using human IL-6 CLEIA (Fujirebio Inc, Tokyo, Japan).

Coronary angiography. Coronary angiography was performed within 3 weeks after surgery in all patients.

Statistical analysis. All statistical analyses were performed using the Statview, version 5.0, software package (SAS Institute, Cary, NC). Data are presented as the mean \pm standard deviation in the text and tables and as the mean \pm standard error in the graphs. The clinical profiles of the 3 groups were compared using $\chi^{2}$ tests or Fisher's exact probability tests for qualitative variables and unpaired $t$ tests or the Mann-Whitney $U$ test for quantitative variables. Within the groups, post hoc multiple comparisons were made using Tukey's test. A repeated measures analysis of variance was performed to compare the laboratory parameters among the 3 groups. If significant differences were found, Bonferroni's corrected comparisons with Student's $t$ tests were made at individual observation times within the groups.

\section{RESULTS}

\section{Perioperative Clinical Data}

The preoperative patient data are summarized in Table 1. No significant differences were detected in the clinical variables among the 3 groups. Complete revascularization

TABLE 1. Preoperative characteristics

\begin{tabular}{|c|c|c|c|c|}
\hline Variable & Open group $(n=25)$ & Nonsuction group $(n=25)$ & Closed group $(n=25)$ & $P$ value \\
\hline Age, y & $66.2 \pm 9.3$ & $68.2 \pm 8.6$ & $66.1 \pm 8.7$ & .68 \\
\hline Male/female, $\mathrm{n}$ & $16 / 9$ & $18 / 7$ & $19 / 6$ & .64 \\
\hline $\mathrm{BMI}, \mathrm{kg} / \mathrm{m}^{2}$ & $22.9 \pm 2.7$ & $24.3 \pm 3.1$ & $24.4 \pm 3.3$ & .17 \\
\hline $\mathrm{BSA}, \mathrm{m}^{2}$ & $1.63 \pm 0.2$ & $1.67 \pm 0.15$ & $1.67 \pm 0.2$ & .59 \\
\hline LVEF, \% & $46.9 \pm 14.6$ & $52.2 \pm 12.9$ & $50.6 \pm 10.6$ & .37 \\
\hline CCS score & $1.84 \pm 0.69$ & $1.95 \pm 0.51$ & $1.72 \pm 0.61$ & .52 \\
\hline Diseased vessels, n (\%) & $2.8 \pm 0.4$ & $2.6 \pm 0.5$ & $2.8 \pm 0.4$ & .43 \\
\hline Two vessels & $5(20)$ & $8(32)$ & $5(20)$ & .52 \\
\hline Three vessels & $20(80)$ & $17(68)$ & $20(80)$ & .52 \\
\hline Smoking, n (\%) & $12(48)$ & $10(40)$ & $12(48)$ & .81 \\
\hline Creatinine, $\mathrm{mg} / \mathrm{dL}$ & $0.95 \pm 0.30$ & $1.04 \pm 0.44$ & $0.99 \pm 0.32$ & .70 \\
\hline Diabetes mellitus, n (\%) & $10(40)$ & $11(44)$ & $13(52)$ & .69 \\
\hline Insulin & $5(20)$ & $6(24)$ & $5(20)$ & .92 \\
\hline Oral agents & $5(20)$ & $5(20)$ & $8(32)$ & .92 \\
\hline Hypertension, n (\%) & $19(76)$ & $20(80)$ & $23(92)$ & .30 \\
\hline Hyperlipidemia, n (\%) & $13(52)$ & $13(52)$ & $15(60)$ & .81 \\
\hline \multicolumn{5}{|l|}{ Preoperative medications, n (\%) } \\
\hline ACE inhibitors & $1(4)$ & $2(8)$ & $4(16)$ & .33 \\
\hline $\mathrm{ARBs}$ & $7(28)$ & $11(44)$ & $13(52)$ & .21 \\
\hline$\beta$-Blockers & $12(48)$ & $13(52)$ & $13(52)$ & .95 \\
\hline Calcium channel blockers & $11(44)$ & $9(36)$ & $8(32)$ & .67 \\
\hline Statins & $12(48)$ & $10(40)$ & $13(52)$ & .89 \\
\hline Nitrate agents & $10(40)$ & $11(44)$ & $11(44)$ & .95 \\
\hline
\end{tabular}

Values are expressed as mean $\pm \mathrm{SD}$, or as indicated. $B M I$, Body mass index; $B S A$, body surface area; $L V E F$, left ventricular ejection fraction; $C C S$, Canadian Cardiovascular Society functional class; $A C E$, angiotensin-converting enzyme; $A R B$, angiotensin II receptor blocker. 
TABLE 2. Intraoperative data

\begin{tabular}{|c|c|c|c|c|}
\hline Variable & Open group $(n=25)$ & Nonsuction group $(\mathbf{n}=\mathbf{2 5})$ & Closed group $(\mathbf{n}=\mathbf{2 5})$ & $P$ value \\
\hline \multicolumn{5}{|l|}{ Duration of procedure, min } \\
\hline Operation & $319 \pm 55$ & $301 \pm 40$ & $307 \pm 40$ & .39 \\
\hline Cardiopulmonary bypass & $157 \pm 34$ & $143 \pm 30$ & $152 \pm 29$ & .38 \\
\hline Aortic crossclamp & $124 \pm 30$ & $114 \pm 28$ & $120 \pm 26$ & .55 \\
\hline Total cardioplegia, $\mathrm{mL}$ & $1944 \pm 621$ & $1693 \pm 231$ & $1994 \pm 634$ & .25 \\
\hline Collection with cell saving device during CPB & NA & $1563 \pm 487$ & $1440 \pm 438$ & .34 \\
\hline Total heparin dose, $\times 10^{3} \mathrm{IU} / \mathrm{kg}$ & $19.7 \pm 4.4$ & $22.1 \pm 4.2$ & $20.5 \pm 5.7$ & .25 \\
\hline Need for additional heparin, $\mathrm{n}(\%)$ & $9(36)$ & $10(40)$ & $7(28)$ & .66 \\
\hline Mean ACT during CPB & $557 \pm 96$ & $554 \pm 129$ & $548 \pm 89$ & .92 \\
\hline Total protamine dose, $\mathrm{U} / \mathrm{kg}$ & $27.0 \pm 4.4$ & $28.4 \pm 4.6$ & $28.1 \pm 5.4$ & .44 \\
\hline Number of distal anastomoses, $\mathrm{n}$ & $3.7 \pm 0.9$ & $3.6 \pm 1.0$ & $3.8 \pm 0.9$ & .73 \\
\hline Number of grafts & $2.8 \pm 0.5$ & $2.7 \pm 0.5$ & $2.8 \pm 0.4$ & .56 \\
\hline \multicolumn{5}{|l|}{ Details of grafts, n (\%) } \\
\hline Left ITA & $25(100)$ & $25(100)$ & $24(96)$ & .36 \\
\hline Radial artery & $13(52)$ & $13(52)$ & $14(56)$ & .95 \\
\hline Saphenous veins & $24(96)$ & $23(92)$ & $24(96)$ & .77 \\
\hline
\end{tabular}

Values are expressed as mean $\pm \mathrm{SD}$, or as indicated. $C P B$, Cardiopulmonary bypass; $A C T$, activated clotting time; ITA, internal thoracic artery; $N A$, not applicable.

was achieved in all patients, and no patients were excluded from the study. Also, no significant differences were noted among the 3 groups in the intraoperative variables (Table 2).

\section{Hematocrit and Platelet Count}

No significant differences were found in the perioperative changes in the hematocrit or platelet counts among the 3 groups (Figure 2).

\section{Coagulation and Fibrinolytic Systems}

No significant differences were seen in the perioperative changes in the APTT, PT, or AT (Figure 3, A) among the 3 groups. The mean of ACTs at the induction of $\mathrm{CPB}$ and 1 hour later showed no significant differences among the 3 groups (Table 2). The perioperative levels of TAT, FDPs, D-dimer, PIC, and PAI-1 differed significantly among the 3 groups $(P<.0001$ for each variable; Figures $3, B-F)$. All these variables were identical among the nonsuction and closed groups. In the open group, the TAT, FDP, and D-dimer levels increased during $\mathrm{CPB}$ and peaked at $\mathrm{T} 4$ and then continued to be significantly greater than those in the other 2 groups from T2 through T7. In the nonsuction and closed groups, the TAT levels did not increase during CPB (T2 and T3) but were significantly increased after protamine administration (T3 vs T4, $P=.001$ ). The PIC levels in the open group were increased at $\mathrm{T} 3$ and continued to be significantly greater than those in the other 2 groups from T3 through T7. The PAI-1 levels did not increase until T4 in all groups; however, the PAI-1 levels in the open group tended to be greater than those in the other 2 groups. On the first postoperative morning, the TAT, FDP, D-dimer, PIC, and PAI-1 levels were comparable among the 3 groups.

\section{Inflammation Systems}

No significant differences were found in the perioperative changes in the C3a or IL- 6 levels among the 3 groups (Figure 4).
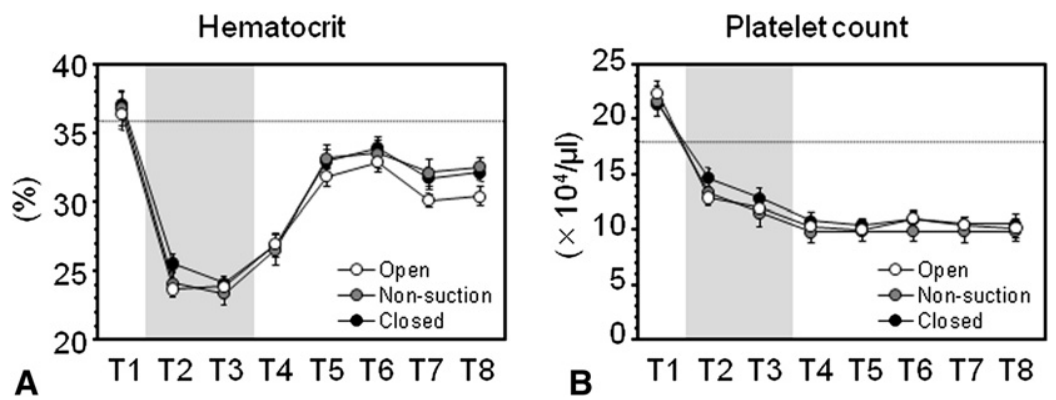

FIGURE 2. Perioperative changes in hematocrit and platelet count. No significant differences found in hematocrit or platelet counts among 3 groups. Dotted lines indicate limit of normal range. Gray columns indicate period of cardiopulmonary bypass (CPB); open circles, open group; semiclosed circles, nonsuction group; closed circles, closed group; $T 1$, before induction of anesthesia; $T 2,1$ hour after initiation of CPB; T3, 10 minutes after aortic declamping; $T 4,5$ minutes after protamine administration; $T 5, T 6$, and $T 7,1,3$, and 6 hours after the of $\mathrm{CPB}$, respectively; $T 8$, first postoperative morning. 

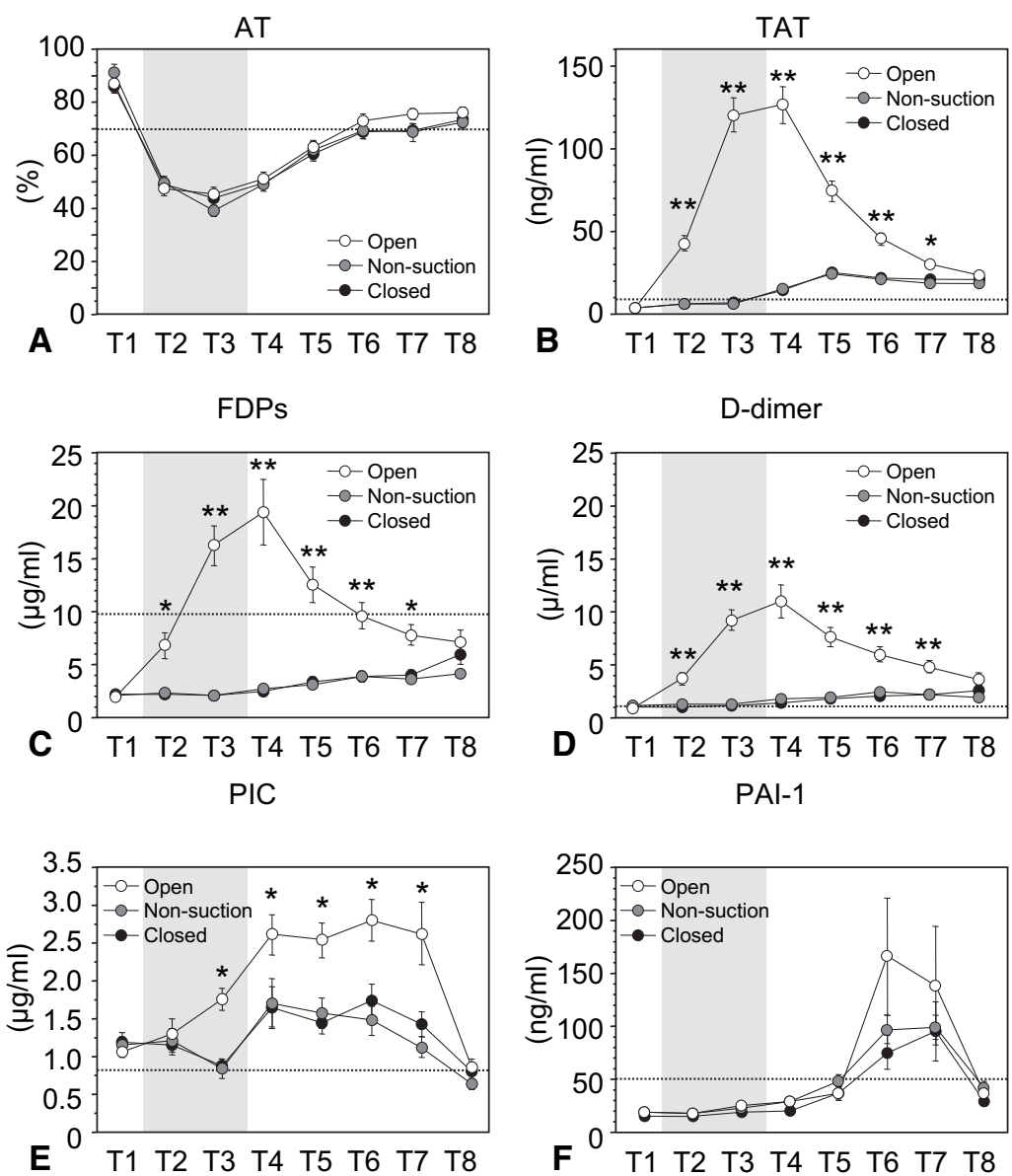

FIGURE 3. Perioperative change in coagulofibrinolysis markers. A, antithrombin III (AT); B, thrombin-antithrombin III complex (TAT); C, fibrinogen degradation products (FDPs); D, D-dimer; E, plasmin- $\alpha 2$ plasmin inhibitor complex (PIC); and F, plasminogen activator inhibitor-1 (PAI-1) levels. No significant differences found in AT among 3 groups. $* P<.01$ and $* * P<.001$ between open and nonsuction or closed group. Dotted lines indicate limit of normal range. Gray columns indicate period of cardiopulmonary bypass (CPB); open circles, open group; semiclosed circles, nonsuction group; closed circles, closed group; $T 1$, before induction of anesthesia; $T 2,1$ hour after initiation of CPB; $T 3,10$ minutes after aortic declamping; $T 4,5$ minutes after protamine administration; $T 5, T 6$, and $T 7,1,3$, and 6 hours after the of $\mathrm{CPB}$, respectively; $T 8$, first postoperative morning.

\section{Postoperative Blood Loss and Blood Product Use}

Postoperative blood loss during the first 6,12 , and 24 hours tended to be greater in the open group than in the other 2 groups, although this difference was not significant (Table 3).
The transfusion of PRBCs during CPB was comparable among the 3 groups; however, transfusions of PRBCs after the weaning of $\mathrm{CPB}$ tended to be greater in the open group than in the other 2 groups (open vs nonsuction or closed
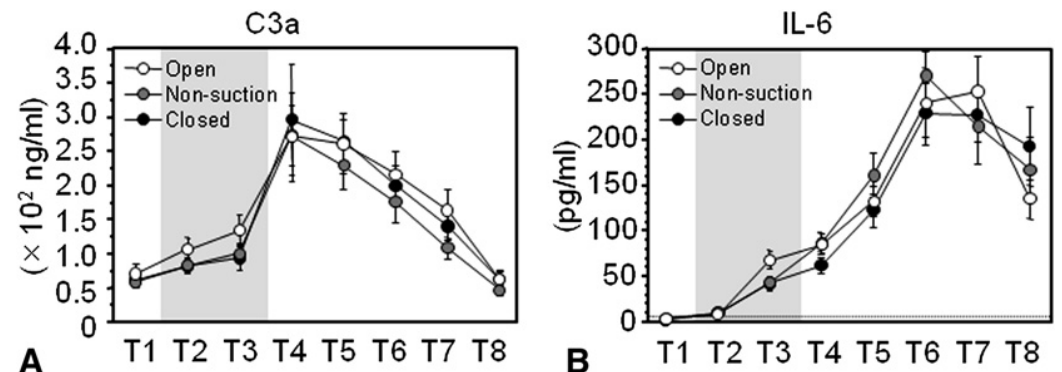

FIGURE 4. Perioperative changes in $\mathrm{C} 3 \mathrm{a}$ and interleukin $(I L)-6$ levels. No significant differences among groups. Dotted lines indicate limit of normal range. Gray columns indicate period of cardiopulmonary bypass $(C P B)$; open circles, open group; semiclosed circles, nonsuction group; closed circles, closed group; $T 1$, before induction of anesthesia; $T 2,1$ hour after initiation of CPB; $T 3,10$ minutes after aortic declamping; $T 4,5$ minutes after protamine administration; $T 5$, $T 6$, and $T 7,1,3$, and 6 hours after the of $\mathrm{CPB}$, respectively; $T 8$, first postoperative morning. 
TABLE 3. Perioperative data and outcomes

\begin{tabular}{|c|c|c|c|c|}
\hline Variable & Open group $(n=25)$ & Nonsuction group $(n=25)$ & Closed group $(n=25)$ & $P$ value \\
\hline Lactate on ICU admission, $\mathrm{mmol} / \mathrm{L}$ & $2.0 \pm 0.9$ & $2.0 \pm 0.8$ & $1.9 \pm 0.8$ & .78 \\
\hline $\begin{array}{l}\text { Postoperative maximum C-reactive } \\
\text { protein, } \mathrm{mg} / \mathrm{dL}\end{array}$ & $17.0 \pm 3.3$ & $19.3 \pm 5.6$ & $19.0 \pm 4.7$ & .24 \\
\hline \multicolumn{5}{|l|}{ Postoperative blood loss, $\mathrm{mL}$} \\
\hline Within $6 \mathrm{~h}$ & $274 \pm 139$ & $215 \pm 72$ & $229 \pm 94$ & .16 \\
\hline Within $12 \mathrm{~h}$ & $382 \pm 177$ & $327 \pm 118$ & $335 \pm 102$ & .35 \\
\hline Within $24 \mathrm{~h}$ & $572 \pm 239$ & $457 \pm 147$ & $448 \pm 118$ & .55 \\
\hline \multicolumn{5}{|l|}{ Transfusion of blood products } \\
\hline Total PRBC, U & $10.7 \pm 4.9$ & $8.6 \pm 5.7$ & $8.9 \pm 5.5$ & .35 \\
\hline During CPB & $3.4 \pm 2.7$ & $3.3 \pm 2.4$ & $3.3 \pm 2.8$ & .22 \\
\hline After CPB & $7.2 \pm 3.2$ & $5.3 \pm 5.1$ & $5.6 \pm 3.6$ & .19 \\
\hline Total FFP, U & $14.6 \pm 6.2$ & $10.6 \pm 4.8$ & $10.6 \pm 4.7$ & .15 \\
\hline Need for platelets, n (\%) & $4(16)$ & $2(8)$ & $1(4)$ & .33 \\
\hline \multicolumn{5}{|l|}{ Postoperative complications, n (\%) } \\
\hline Re-exploration for bleeding & $0(0)$ & $0(0)$ & $0(0)$ & NA \\
\hline New atrial fibrillation & $7(28)$ & $6(24)$ & $8(32)$ & .82 \\
\hline Stroke & $1(4)$ & $1(4)$ & $0(0)$ & .60 \\
\hline Deep sternal infection & $2(8)$ & $0(0)$ & $0(0)$ & .13 \\
\hline Renal failure (creatine $>2.0 \mathrm{mg} / \mathrm{dL}$ ) & $1(4)$ & $2(8)$ & $2(8)$ & .80 \\
\hline IABP support & $0(0)$ & $0(0)$ & $0(0)$ & NA \\
\hline Early graft patency, $\%$ & 93.5 & 97.1 & 98.9 & .11 \\
\hline Left ITA & 100 & 100 & 100 & NA \\
\hline Radial artery & 92.3 & 92.3 & 100 & .48 \\
\hline Saphenous veins & 83.9 & 96.8 & 96.8 & .13 \\
\hline
\end{tabular}

Values are expressed as mean $\pm \mathrm{SD}$, or as indicated. ICU, Intensive care unit; $P R B C$, packed red blood cells; $C P B$, cardiopulmonary bypass; $F F P$, fresh frozen plasma; $C r e$, creatinine; $I A B P$, intra-aortic balloon pump; ITA, internal thoracic artery; $N A$, not applicable.

group, $P=.013$ and $P=.091$, respectively). More perioperative total transfusions of PRBCs or fresh frozen plasma occurred in the open group than in the nonsuction and closed groups, although the differences were not significant (Table 3).

\section{Early Graft Patency}

The overall graft patency rate was $95.4 \%$. The patency rates of the internal thoracic artery and radial artery were similar among the 3 groups (Table 3). The saphenous vein graft patency rate in the open group was lower than that in the nonsuction and closed groups, although the differences were not significant (open vs nonsuction or closed group, $P=.17$ and $P=.091$, respectively).

\section{DISCUSSION}

The results from the present prospective, randomized study have provided a clear comparison between cardiotomy suction and open venous reservoirs in the coagulofibrinolysis and inflammation systems, excluding the bias of hemodilution and anticoagulation. We found that the use of cardiotomy suction was the leading cause of coagulofibrinolysis activation and that the use of open venous reservoirs, which have 2 nonphysiologic aspects of blood-air interface and blood retainment, did not affect the coagulofibrinolysis system.
The present results show that thrombin was generated during CPB with the use of cardiotomy suction. Although the use of cardiotomy suction has been considered to influence the coagulation pathway owing to both the suction force and the blood contact with wound tissue factor, Fabre and colleagues ${ }^{18}$ reported that the suction force is not associated with thrombin formation. The present results that the open group alone showed a significant TAT elevation is consistent with previous clinical and hematologic observations that blood interference with wound tissue factor with the use of cardiotomy suction results in thrombin generation through the extrinsic coagulation pathway in cardiac surgery. ${ }^{14,19,20}$

The lack of thrombin generation in the nonsuction and closed groups, in which cardiotomy suction was eliminated and the extrinsic coagulation pathway was not activated, provides important data about the mechanism of action of heparin and the extent of heparinization necessary for CPB. Heparin acts as an anticoagulant by amplifying ATIII, which blocks the coagulation factors XIIa, XIa, IXa, Xa, and thrombin (IIa) in the intrinsic coagulation pathway. ${ }^{10} \mathrm{Al}$ though the contact of blood with a negatively charged circuit surface activates the intrinsic coagulation pathway, in our study, thrombin activity was almost completely suppressed by heparinization in the nonsuction and closed groups. These observations indicate that heparin successfully blocks 
the upstream coagulation factors (XIIa, XIa, IXa, and Xa) in the intrinsic coagulation pathway before reaching the stage of thrombin activation. The lack of participation of the intrinsic coagulation pathway in thrombin activation during $\mathrm{CPB}$ can also explain a previous finding that patients lacking factor XII, a trigger enzyme in the intrinsic coagulation pathway, have an extent of perioperative thrombin activation equivalent to that of normal cardiac surgery patients undergoing CPB. ${ }^{21}$ Furthermore, if heparin-coated circuits were used without cardiotomy suction, the magnitude of heparinization can be reduced up to the level at which thrombin activation starts to be observed, without applying empiric anticoagulation protocols. ${ }^{10,11}$ Despite the increase in the hemostatic markers (TAT, FDPs, D-dimer, PIC) observed only in the open group, the total heparin dose, mean ACT during $\mathrm{CPB}$, and perioperative change of AT showed no differences among the 3 groups. These findings lead to the questions of whether the elevated hemostatic markers resulting from the use of cardiotomy suction really indicate the activation of systemic coagulability; and whether ACT is appropriate for an anticoagulation assessment during $\mathrm{CPB}$.

The time lag in the elevation of TAT, PIC, and PAI-1 levels in the open group was consistent with time course of the hemostatic mechanism. When vascular injury occurs and blood interferes with tissue factor, hemostatic action occurs in the following order: fibrin network formation occurs through the coagulation pathway, fibrin is removed by fibrinolysis, and fibrinolysis is then suppressed. ${ }^{10,22}$ The TAT, PIC, and PAI-1 levels determine the extent of activity for coagulation, fibrinolysis, and fibrinolysis inhibition, respectively, and the time course of these markers in the open group in our study was consistent with a hemostatic mechanism. Fibrinolysis is activated by the retransfusion of pericardial wound blood, which is rich in tissue plasminogen activator. ${ }^{23}$ We found that the peak D-dimer levels were different from the PIC levels in the open group, although both are fibrinolytic markers. This discrepancy could have resulted from differences in how these markers specifically characterize fibrinolysis. PIC represents the amount of plasmin formation, indicating fibrinolytic activity. In contrast, D-dimer represents the amount of degeneration products from fibrin by fibrinolysis, and the amount of D-dimer depends on the amount of fibrin in the systemic circulation in addition to fibrinolytic activity. Thus, the peak of D-dimer levels at the end of CPB in the open group indicated that cardiotomy suction provides sufficient fibrin to the systemic circulation.

PAI-1 has recently been reported as a remarkable marker to predict early vein graft occlusion after $\mathrm{CABG}^{24-26}$ The previous findings of the relation between PAI-1 elevation and vein graft occlusion could explain the present results in which the open group, with the greatest values of PAI-1, showed the lowest graft patency rate of the saphenous vein grafts. ${ }^{24-26}$ Any method to suppress the postoperative PAI-1 elevation might be helpful for obtaining better vein graft patency. The relationships between the use of cardiotomy suction, postoperative PAI-1 elevation, and early vein graft occlusion remain to be examined in a larger study population.

The similar results of C3a and IL-6 levels among the 3 groups showed that neither cardiotomy suction nor an open venous reservoir influences the inflammation system. Because even the closed group without cardiotomy suction or open venous reservoirs resulted in elevation of the inflammatory markers suggests that extracorporeal circulation through a heart-lung machine is the leading cause of perioperative inflammatory activation. The comparative results of the postoperative maximum $\mathrm{C}$-reactive protein levels also suggested that the extent of postoperative inflammatory activation was not different among the 3 groups. The average peak IL- 6 value in all patients in the present study was $225 \mathrm{pg} / \mathrm{mL} 6$ hours after surgery. Mazzei and colleagues ${ }^{4}$ reported that the peak IL- 6 value in CABG patients using a minimal extracorporeal circulation system and in $\mathrm{OPCAB}$ patients was 167 and $181 \mathrm{pg} / \mathrm{mL} 6$ hours after surgery, respectively. The miniaturization of circuits and the elimination of $\mathrm{CPB}$ might suppress perioperative inflammatory activation, although a randomized study is necessary to confirm this speculation.

The identical changes in platelet counts among the 3 groups in our study have clearly shown that neither cardiotomy suction nor an open venous reservoir is associated with perioperative thrombocytopenia. In our study, we set an identical priming volume of $1300 \mathrm{~mL}$ in all groups to avoid the effect of hemodilution, resulting in identical platelet counts. In contrast, Sakwa and colleagues ${ }^{1}$ compared closed and miniaturized circuits (a priming volume of $900 \mathrm{~mL}$ ) with conventional open circuits (a priming volume of $1850 \mathrm{~mL}$ ) and concluded that closed and miniaturized circuits significantly preserved platelet count. Thus, it is possible that the difference in the findings between the 2 studies resulted from the difference in the priming volume. This possibility suggests that hemodilution by the priming volume in a $\mathrm{CPB}$ circuit largely influences perioperative thrombocytopenia.

For perioperative blood conservation, the alternative use of cell-saving devices, which has been suggested in an evidence-based review, ${ }^{27}$ instead of cardiotomy suction, might be justified by the several negative results associated with the use of cardiotomy suction found in our study. The open group, which used cardiotomy suction, was associated with more activation in coagulofibrinolysis and worse results, with an increase in postoperative blood loss and perioperative transfusions, compared with the other 2 groups. However, Rubens and colleagues ${ }^{15}$ reported negative results with the alternative use of cell-saving devices for perioperative blood conservation. This discrepancy in the findings between the 2 studies could have been because the study by 
Rubens and colleagues ${ }^{15}$ had included patients undergoing aortic valve surgery and with different protocols of blood product use established, such as re-administration of postoperative scavenged mediastinal blood. If cell-saving devices are used, they can be disadvantageous because of the excessive loss of coagulation factors and the delay of blood return. A Canadian national survey reported that in $15(41.7 \%)$ of 36 centers, cardiotomy suction was eliminated in some patients, particularly for CABG, and that 5 of those centers established a volume cutoff for the conversion from the use of a cell-saving device to the use of cardiotomy suction. ${ }^{28}$ Therefore, for the alternative use of cell-saving devices, an optimal volume cutoff for the conversion needs to be determined in future studies, although the elimination of cardiotomy suction is currently impractical in some cardiac surgeries such as redo valve procedures.

The present study had several limitations. First, for the clinical outcomes, such as postoperative bleeding, transfusions required, and graft patency, the sample size was too small to allow comparisons among the groups or to rule out a type II statistical error. For vein graft patency, a power estimation analysis suggested that 97 patients per group were needed to obtain an $80 \%$ power goal between 2 groups, considering an $\alpha$ error level of 5\% and expecting the incidence of vein graft patency to decrease from $96 \%$ to $84 \%$. Second, we did not quantify the volume of blood retransfused through cardiotomy suction, because an additional cardiotomy reservoir and the temporary retainment of the blood in the reservoir would have been necessary for the quantification, and we were concerned that the additional canister and blood retainment might affect the hemostatic results. Third, with regard to the inflammatory system, our study evaluated only the representative inflammatory markers of C3a and IL-6; thus, other inflammatory marker levels were unknown. Fourth, our study did not evaluate postoperative cognitive function. The association between the use of cardiotomy suction and postoperative cognitive dysfunction has been examined, although the results have been controversial. ${ }^{2,15,16,27}$

\section{CONCLUSIONS}

The present study had the following 3 findings. First, the use of cardiotomy suction, but not open venous reservoirs, caused perioperative activation of coagulation and fibrinolysis. Second, the current heparin protocol (celite ACT more than 400 seconds) completely suppressed thrombin activation when cardiotomy suction was eliminated. Third, neither cardiotomy suction nor open venous reservoirs affected inflammation marker levels and platelet depletion. These findings could be helpful for determining optimal anticoagulation during CPB, for appropriately use of an open venous reservoir or cardiotomy suction, and to achieve less-invasive and more biocompatible use of CPB to improve the outcomes after cardiac surgery.
We appreciate the assistance of the Departments of Anesthesiology and Extracorporeal Circulation, the Central Clinical Laboratory (Osaka City University Hospital, Osaka, Japan), and the Laboratory of Statistics (Osaka City University Graduate School of Medicine, Osaka, Japan).

\section{References}

1. Sakwa MP, Emery RW, Shannon FL, Altshuler JM, Mitchell D, Zwada D, et al. Coronary artery bypass grafting with a minimized cardiopulmonary bypass circuit: a prospective, randomized trial. J Thorac Cardiovasc Surg. 2009;137: 481-5.

2. Liebold A, Khosravi A, Westphal B, Skrabal C, Choi YH, Stamm C, et al. Effect of closed minimized cardiopulmonary bypass on cerebral tissue oxygenation and microembolization. J Thorac Cardiovasc Surg. 2006;131:268-76.

3. Zangrillo A, Garozzo FA, Biondi-Zoccai G, Pappalardo F, Monaco F, Crivellari M, et al. Miniaturized cardiopulmonary bypass improves short-term outcome in cardiac surgery: a meta-analysis of randomized controlled studies. J Thorac Cardiovasc Surg. 2009;139:1162-9.

4. Mazzei V, Nasso G, Salamone G, Castorino F, Tommasini A, Anselmi A. Prospective randomized comparison of coronary bypass grafting with minimal extracorporeal circulation system (MECC) versus off-pump coronary surgery. Circulation. 2007;116:1761-7.

5. Formica F, Broccolo F, Martino A, Sciucchetti J, Giordano V, Avalli L, et al. Myocardial revascularization with miniaturized extracorporeal circulation versus off pump: evaluation of systemic and myocardial inflammatory response in a prospective randomized study. J Thorac Cardiovasc Surg. 2009;137:1206-12.

6. Miyaji K, Kohira S, Miyamoto T, Nakashima K, Sato H, Ohara K, et al. Pediatric cardiac surgery without homologous blood transfusion, using a miniaturized bypass system in infants with lower body weight. J Thorac Cardiovasc Surg. 2007; 134:284-9.

7. Puskas JD, Steele M. Would you like some cardiopulmonary bypass with your coronary revascularization? Circulation. 2007;116:1756-8.

8. Aviles RJ, Martin DO, Apperson-Hansen C, Houghtaling PL, Rautaharju P, Kronmal RA, et al. Inflammation as a risk factor for atrial fibrillation. Circulation. 2003;108:3006-10.

9. Edmunds LH Jr, Colman RW. Thrombin during cardiopulmonary bypass. Ann Thorac Surg. 2006;82:2315-22.

10. Hammon JW. Extracorporeal circulation: the response of humoral and cellular elements of blood to extracorporeal circulation. In: Cohn LH, ed. Cardiac surgery in the adult. 3rd ed. New York: McGraw-Hill; 2007:370-89.

11. Ovrum E, Brosstad F, Am Holen E, Tangen G, Abdelnoor M. Effects on coagulation and fibrinolysis with reduced versus full systemic heparinization and heparin-coated cardiopulmonary bypass. Circulation. 1995;92:2579-84.

12. Tanaka H, Oshiyama T, Narisawa T, Mori T, Masuda M, Kishi D, et al. Clinical study of biocompatibility between open and closed heparin-coated cardiopulmonary bypass circuits. J Artif Organs. 2003;6:245-52.

13. Schonberger JP, Everts PA, Hoffmann JJ. Systemic blood activation with open and closed venous reservoirs. Ann Thorac Surg. 1995;59:1549-55.

14. de Somer F, van Belleghem Y, Caes F, Francois K, van Overbeke H, Arnout J, et al. Tissue factor as the main activator of the coagulation system during cardiopulmonary bypass. J Thorac Cardiovasc Surg. 2002;123:951-8.

15. Rubens FD, Boodhwani M, Mesana T, Wozny D, Wells G, Nathan HJ. The cardiotomy trial: a randomized, double-blind study to assess the effect of processing of shed blood during cardiopulmonary bypass on transfusion and neurocognitive function. Circulation. 2007;116(Suppl):I89-97.

16. Djaiani G, Fedorko L, Borger MA, Green R, Carroll J, Marcon M, et al. Continuous-flow cell saver reduces cognitive decline in elderly patients after coronary bypass surgery. Circulation. 2007;116:1888-95.

17. Chandler WL. Effects of hemodilution, blood loss, and consumption on hemostatic factor levels during cardiopulmonary bypass. J Cardiothorac Vasc Anesth. 2005; 19:459-67.

18. Fabre O, Vincentelli A, Corseaux D, Juthier F, Susen S, Bauters A, et al. Comparison of blood activation in the wound, active vent, and cardiopulmonary bypass circuit. Ann Thorac Surg. 2008;86:537-41.

19. Philippou H, Adami A, Davidson SJ, Pepper JR, Burman JF, Lane DA. Tissue factor is rapidly elevated in plasma collected from the pericardial cavity during cardiopulmonary bypass. Thromb Haemost. 2000;84:124-8.

20. Chung JH, Gikakis N, Rao AK, Drake TA, Colman RW, Edmunds LH Jr. Pericardial blood activates the extrinsic coagulation pathway during clinical cardiopulmonary bypass. Circulation. 1996;93:2014-8. 
21. Burman JF, Chung HI, Lane DA, Philippou H, Adami A, Lincoln JC. Role of factor XII in thrombin generation and fibrinolysis during cardiopulmonary bypass. Lancet. 1994;344:1192-3.

22. Gando S. Tissue factor in trauma and organ dysfunction. Semin Thromb Hemost. 2006;32:48-53.

23. Tabuchi N, de Haan J, Boonstra PW, van Oeveren W. Activation of fibrinolysis in the pericardial cavity during cardiopulmonary bypass. J Thorac Cardiovasc Surg. 1993;106:828-33

24. Moor E, Blomback M, Silveira A, Wiman B, Cederlund K, Bergstrand L, et al. Haemostatic function in patients undergoing coronary artery bypass grafting: peroperative perturbations and relations to saphenous vein graft closure. Thromb Res. 2000;98:39-49.
25. Kauhanen P, Siren V, Carpen O, Vaheri A, Lepantalo M, Lassila R. Plasminogen activator inhibitor-1 in neointima of vein grafts: its role in reduced fibrinolytic potential and graft failure. Circulation. 1997;96:1783-9.

26. Rifon J, Paramo JA, Panizo C, Montes R, Rocha E. The increase of plasminogen activator inhibitor activity is associated with graft occlusion in patients undergoing aorto-coronary bypass surgery. Br J Haematol. 1997;99:262-7.

27. Shann KG, Likosky DS, Murkin JM, Baker RA, Baribeau YR, DeFoe GR, et al An evidence-based review of the practice of cardiopulmonary bypass in adults: a focus on neurologic injury, glycemic control, hemodilution, and the inflammatory response. J Thorac Cardiovasc Surg. 2006;132:283-90.

28. Belway D, Rubens FD, Wozny D, Henley B, Nathan HJ. Are we doing everything we can to conserve blood during bypass? A national survey. Perfusion. 2005;20:237-41. 